\title{
Analysing ESL Students' Perceptions towards Oral Communication for Social and Occupational Purposes
}

\author{
Fauzilah Md Husain \\ School of Languages, Literacies and Translation, Universiti Sains Malaysia \\ 11800 Penang, Malaysia \\ E-mail: fauzilah@usm.my \\ Malini Ganapathy (Corresponding author) \\ School of Languages, Literacies and Translation, Universiti Sains Malaysia \\ 11800 Penang, Malaysia \\ E-mail: malinik@usm.my \\ Akmar Mohamad \\ School of Languages, Literacies and Translation, Universiti Sains Malaysia \\ 11800 Penang, Malaysia \\ E-mail: akmar@usm.my
}

Doi:10.7575/aiac.alls.v.6n.6p.187

URL: http://dx.doi.org/10.7575/aiac.alls.v.6n.6p.187
Received: 06/08/2015

Accepted: 09/10/2015

\begin{abstract}
Fundamental principles of public speaking and appropriate organisational structure of ideas for occupational and social communication are vital aspects for undergraduates as a pathway to overcome employers' grievances on graduates' lack of communication skills (Malaysia Education Blueprint, 2015). This study was undertaken to explore the perceptions of a group of ten students at a tertiary institution in Malaysia to see how they utlise the theories and practice of effective communication skills beyond their course entitled "Oral Communication for Social and Occupational Purposes". Semistructured interviews were conducted with the participants. The study found that these students gained knowledge about effective communication for social and occupational purposes. The findings also indicate that students have benefitted in relation to communication in a formal way especially to higher authorities, and sharpening their communication and presentation skills. However, there were shortcomings that need to be addressed, particularly related to methods of teaching Oral Communication for Social and Occupational Purposes, time constraint in preparing for the tutorial sessions and producing a good quality video.
\end{abstract}

Keywords: Social and Occupational, Communication, Oral skills, Theories and Practice

\section{Introduction}

The advent of digital technology has reinforced the significance of English as a medium of communication globally irrespective of social, linguistic and cultural origins. Communication skills facilitate a myriad of life opportunities. The higher education sector is held liable to develop students' oral communication skills which impact on their academic performance, professional development, personal and social efficacy that will prepare them for their workplace environment. It also underpins the development of a highly skilled, innovative workforce as a critical enabling factor for social, cultural, and economic growth. Mechraoui et al. (2013) reiterate that the current forces of transformation in the labour market has resulted in employees not just being able to have industry-related technical knowledge but be able to relevantly apply soft skills that enable them to think critically, communicate well and handle problem solving situations. These soft skills are industrial prerequisites for current job employment.

Malaysian tertiary students are knowledgeable but in terms of applying it in the real world is questionable (Kadir et al., 2014). The Malaysia Education Blueprint (2015:6) advocates that tertiary institutions have to ensure that their courses are able to harness "graduates with directly employable skills, values and behaviours that match industry demand". Currently, the standards of graduates are incompatible with employers highlighting that graduates lack the requisite knowledge, skills and attitudes. There is a dire need to address this mismatch as technological severance diversifies industries and reforms the nature of jobs available.

It is evident that there is a pressing need for graduates to master job market skills that encompass critical thinking and communication skills, and English language proficiency that are vital for success in the $21^{\text {st }}$ century. Employers lament that graduates fall short of displaying good communication in English and lack soft skills (Malaysia Education Blueprint, 2015). One of the initiatives of higher education institutions is to offer English for Occupational Purposes with the aim of preparing students with vital employability skills. The purpose of the present study was to explore the perceptions of English as a Second Language (ESL) to students at a tertiary institution in Malaysia to see how they 
utilise the theories and practice of effective communication skills beyond their course titled "Oral Communication for Social and Occupational Purposes".

\section{Literature Review}

While the literature on the university course, Oral Communication for Social and Occupational Purposes is scarce, there has been some research shedding light on the topic. Literature states that communication skills are considered as one of the desired skills in new graduates by employers (Cappel, 2011; Gray, 2010; Kavanagh \& Drennan, 2008). A study conducted by Robles (2012) identified communication skills as the top 10 soft skills perceived as the most important by 49 business executives and these skills can be promoted by educators in their curriculum to improve the employability of graduates. The literature has also identified oral communication skills as the most pertinent and predominantly used at the workplace (Mohamad Zasfirul Zainal Abidin, 2010; Stapa et al., 2008; Luna, 2004).

In a study to investigate the relevance of the tertiary English language proficiency curriculum to the workplace, Talif and Noor (2009) used structured interviews to solicit the opinions of students at four public tertiary institutions of higher learning in Malaysia. 86 final year students who were involved in industry-linkage programmes that lasted between four and six months were interviewed. Most of the students from one of the universities were satisfied with the English language courses provided by the university in preparing them for work. The findings indicate that a high degree of speaking ability is required to perform a majority of the tasks at workplaces. $86 \%$ of their respondents mentioned that public speaking skills were important in building confidence to deliver an effective oral presentation. The respondents felt that they needed to work on their confidence level when giving presentations and they would like to improve their speaking and discussion skills before their graduation.

Hanafi Zaid and Kamarudin (2011) investigated the present and future Oral Communication Needs of Mechanical Engineering undergraduate students at Universiti Teknologi Malaysia. Most of the students in the study admitted that they lacked confidence to communicate. The results obtained in the study show that the students believed that giving presentations which are formal is one way of practising their communication skills. The students also perceived being able to participate in group discussions as a potential future need for the workplace.

Moreover, a study was conducted to investigate the types of English oral communication difficulties and communication strategies of Diploma of Hotel Management students at UiTM (Radzuan \& Kaur, 2011). A convenience sampling method was used to select the respondents where a questionnaire was administered among the 100 Diploma of Hotel Management students at a UiTM branch campus in Penang, Malaysia. 16 students out of 100 respondents volunteered to participate in the focus group interviews and journal writing. Findings revealed that students had limited vocabulary as they think in Malay and translated their ideas into English. This is one factor which created difficulties in oral communication. In addition, the journals revealed that students took a long time to process and plan for their English oral presentations. They stated that they needed more time to write the sentences before producing them. Time constraint was a key challenge for students in this course.

Additionally, a study was carried out to investigate the factors which create anxiety among 44 final year University Malaysia Pahang engineering students when giving their Undergraduate Research Project (URP) Oral Presentations (Zulkurnain \& Kaur, 2011). Students are required to deliver their URP in English as part of graduation requirements. Each student was given 15 minutes for presentation and another 15 minutes for the Question and Answer session. Focus group interviews were conducted with the 44 students. All the interviews were recorded and transcribed manually. The key finding highlighted that one of the sources of anxiety was the low English proficiency of the students. This had a negative effect on their oral presentation which, in turn, also affected the overall marks obtained for their URP.

Besides, Masmaliyeva (2014) conducted a study among 21 undergraduate students in a first year Advanced English Speaking class in the Department of English Language and Literature at a large Mid Anatolian Public University in Turkey. The objective of the research was to investigate their perceptions regarding oral presentations. Data was collected through surveys, video recordings of students' oral presentations, observations and taking note of students' class attendance. Although anxiety has been identified by researchers as a negative aspect of delivering oral presentations, $90 \%$ of the respondents stated that they were comfortable when delivering oral presentations. The majority of the participants stated that they thoroughly enjoyed their class. They also reported that their confidence increased as a result of repeatedly making presentations. This led to students' better fluency and accuracy. Previous studies have indicated that one of the challenges of using oral presentations in the classroom is boredom. This aspect was reflected in this study where $16 \%$ of the participants reported that they felt bored during oral presentations.

In another study by Al-Nouh, Abdul-Kareem and Taqi (2015) which investigated college students' perception of the difficulties they faced in oral presentations used as a form of assessment, advocated pertinent insights on challenges faced by students during the course. The participants were 500 college students undergoing a four-year pre-service teacher education program at the College of Basic Education in Kuwait City, Kuwait. Data was collected through a questionnaire and interviews with instructors. One of the findings portrayed that about $40 \%$ of the students said they "sometimes" dislike oral presentations. The study also indicated that $41.9 \%$ of the students "always" brought their oral presentation notes although they were well-prepared for the presentations. $39.2 \%$ of the respondents reported "always" feeling worried, even if they had made preparations for the oral presentations. $55.7 \%$ said they felt apprehensive of oral presentations. The data also revealed problems such as lack of fluency, grammar, and vocabulary knowledge in which students translate from Arabic to English. However, it is interesting to note that students evaluated themselves as having confidence in their abilities. 
Furthermore, a study to investigate students' perceptions of the development of their communication skills during the English classes was conducted at the Faculty of Civil Engineering and Architecture, University of Niš, Serbia (Živković, 2014). The findings of the study show that students perceived the importance of oral presentations in developing communication skills for future professional surrounding. The students believed that doing oral presentations would help develop their communication skill which is an essential skill for career advancement.

One more study conducted by Ramírez (2010) investigating students' perception regarding the development of their oral skills during the 'Professional Development Program for Teachers of English' in Colombia. A questionnaire was designed to investigate students' perception of the development of their skills in speaking English. Semi-structured interviews and class observation were also used in collecting data. The respondents were 45 students between the ages of 17-25. The majority of the participants indicated that they perceived that their oral skills had improved in terms of pronunciation and intonation. However, they were still fearful of making mistakes when participating in class discussions and were not confident. The students perceived their grades positively.

Last but not the least, a study to investigate the English communicative skills of 130 fourth year undergraduate engineering students was conducted at two public universities in Thailand by (Rajprasit, Pratoomrat, \& Wang, 2015). The aim of the study was to identify the perceptions of Thai engineering students in a government university, and the problems they experienced with both the English language and their communication abilities. The qualitative and quantitative methods were used to analyse the data. Data was collected through a survey and instructors' interviews showed that although students perceived their English proficiency as 'fair', they reported that they had difficulties with their productive skills, such as speaking and writing, in English communication. Of all the four skills, it was found that the students performed best in reading and the worse skill was speaking. The data also revealed that these students had unrealistic language learning goals. Thus it can be concluded that the final-year students may face difficulties with communicating in the workplace.

This study seeks to present ESL students' perceptions towards their course: Oral Communication for Social and Occupational Purposes in one public research university in Malaysia.

\subsection{Research Question}

The study was guided by the following research questions:

1. What are students' perceptions of Oral Communication for Social and Occupational Purposes?

2. What are the challenges of Oral Communication for Social and Occupational Purposes?

\section{Methodology}

\subsection{Research Design}

The study employed in-depth semi-structured interviews to provide reliable, detailed and accurate observation of ESL Students' Perceptions towards Oral Communication for Social and Occupational Purposes.

\subsection{Research Sample}

The research sample involved ten ESL final year students from a research university in Malaysia. As a measure of safeguarding the privacy of the students involved in this study, their names will not be revealed. Instead, the student will be named as Student A, Student B, Student C, Student D, Student E, Student F, Student G, Student H, Student I and Student J. The students were chosen based on purposive sampling where their test grades were taken into account. Students with low grades of $\mathrm{C}$ and $\mathrm{D}$ were chosen on the premise that if low achievers benefitted from the course. Based on this criterion of selection, ten students were identified.

\subsection{Research Instrument}

The research instrument used in this study was a semi-structured interview which was constructed based on the Instructional Planning of the course and items that were necessary to match the research objective of the study. An interview schedule was constructed in order to enable the formulation of appropriate questions that will facilitate the collection of the required data to answer the research questions. A phenomenological qualitative analysis was used to analyse the data gathered from the interviews through an emergent strategy which is vital to allow the method of analysis to follow the nature of the data itself. The responses provided by the students were transcribed and analysed deductively.

\subsection{Procedure}

Students were interviewed at the end of the course which was week 14. Each student was interviewed on an individual basis in the researchers' office. Each researcher interviewed three students and one researcher had interviewed four students. Students were asked on their subject matter experience, the practicality of the theories, positive and negative experiences of the course, benefits of the course and challenges experienced during the course.

\section{Findings and Discussion}

The interviews were analysed to determine emerging themes among responses. The following themes were identified:

1. Subject matter experience

2. Cost benefits for future occupational purposes

3. Cost benefits for future social purposes 
4. Theoretical applications for future occupational purposes

5. Theoretical applications for future social purposes

6. Issues and challenges experienced during the course

The results of the interviews will be discussed according to the emerging themes. Each theme is discussed in turn.

\subsection{Subject Matter Experience}

This theme represents the students' experience with the content of the course. Overall, the students felt that they had acquired new knowledge and were able to apply the theories learnt during the discussions in their tutorials. They enjoyed exchanging thoughts and opinions with group members and listening to the opinions of other students during tutorials.

The students also felt that they "learnt about effective communication for social and occupational purposes", "learnt what should and should not be said" and "learnt to convey messages effectively". However, there were students who found "some theories difficult" and "not know how to apply them". Some thought that the lectures were "too long" and "packed with information" and they found it "hard to maintain focus". A few had difficulty with the lecture and tutorial contents as reflected in the following extracts:

"Sometimes, I knew the theories, but I didn't know how to apply them. So the lecturer should create more chances for the students to practise." (Student B)

"I was not sure about the theories. I felt nervous during the forums in tutorials." (Student E)

The students expressed a lack of confidence in their ability to interpret the tutorial and assignment requirements. Student F said,

"I had to read a lot from several sources such as lecture notes, additional materials from the lecturer and online articles. Therefore, I took a lot of time reading and also preparing the answers for the questions. Sometimes I misunderstood the questions."

Student $\mathrm{C}$ stated that he lacked confidence but also added:

"I was nervous at first. I was quite fine later after a few tutorials."

Generally the students viewed their experience with the subject matter in a positive light. They did "enjoy preparing for the tutorials" and felt that the activities that were related to the subject matter were "valuable lessons for the future" as expressed in the following extracts:

"The theories are related to my future occupational life and I will be able to apply the theories without any trouble. I enjoyed the activities during tutorials and lectures.” (Student J)

"I learned how to put all the theories and knowledge that I got from my lectures into practical use in tutorials. There were a lot of group interactions, group work and projects." (Student H)

"I got to learn the theories and guidelines about effective communication, socially and professionally." (Student A)

Talif and Noor (2009) found similar views expressed by their interviewees regarding the English language courses at universities. Their interviewees felt that the courses exposed them to the different speaking tasks needed to be done at the workplace. Their findings also indicate students' desires to improve their speaking skills and build their confidence which Robles (2012) reiterates as vital for educators to emphasise in their curriculum in order to improve the employability of graduates.

\subsection{Cost Benefits for Future Occupational Purposes}

One of the challenges in today's competitive work environment is to be able to communicate effectively with colleagues and clients. The students perceived the significance of oral presentations and group discussions for effective communication in their future professional surrounding. They believed that through collaborating with their group members, they developed skills that would help them deal with situations and problems that they would encounter in the workplace. All the students felt that they learnt important skills that would enhance their employability skills such as:

1. gathering, analysing, planning and presenting information efficiently and accurately for specific audiences

2. thinking critically in solving problems

3. interacting in a professional setting and expressing opinions during discussions

The interviews revealed that the students were positive about the course and they thought that they were learning "how to communicate in a formal way". They pointed out that it taught them how to conduct themselves with their colleagues, superiors, and in a work environment. In addition, they mentioned that the course prepared them for "the forum and 
group discussion" which they will encounter in the real workplace and they felt that they "become more organised and coherent", "are able to deliver information clearly and concisely" and "think critically".

The students felt that participating in the activities and doing the assignments had a positive influence on the development of their oral communication skills for future occupational purposes. Frequent presentations helped them to be more organised and be more aware of the patterns of organisation according to the speech types. They had more experience in gathering information, choosing their sources, and using graphics in presenting information to the audience. They gained from the process of gathering information as they had to "read from various sources and select points". As commented by Student G:

"One of the main requirements at the workplace is to deal with people, whether they are my clients, my superiors or colleagues. This course guides me in communicating with them effectively. This is an important skill to maintain a good relationship with others and get jobs done quickly."

Other comments made regarding the benefits of the course are:

"The course is useful as it gives me ideas on what to expect when I start working." (Student B)

"I have learnt that every form of communication has a purpose and its delivery is important."

(Student D)

Comments from the students showed that they considered the course beneficial as it helped them to "be more confident in their presentations and prepare for the working world" as expressed in the following extracts:

"I felt less nervous after speaking a few times in front of the class." (Student C)

"I have gained more confidence and I could gain my audience's attention easily." (Student E)

"I am now calmer when I express my ideas in front of the public." (Student A)

The students agreed that they needed to develop their speaking and presentation skills for the workplace and that they needed practice and assistance in developing their persuasive skills. They mentioned:

"I managed to improve my understanding of the persuasive speech after the presentations."

(Student J)

"Now I realise that we have to use different words in order to persuade effectively." (Student I)

"I also get to polish my communication skills to prepare myself for work." (Student F)

The responses from the students indicate that they were aware of employers' expectations in terms of communication (Cappel, 2011; Gray, 2010; Kavanagh \& Drennan, 2008). Similar views regarding the improvement of confidence level were also expressed by the participants in other studies (Masmaliyeva, 2014; Hanafi Zaid \& Kamarudin, 2011; Talif \& Noor, 2009)

\subsection{Cost Benefits for Future Social Purposes}

The students mentioned some positive aspects of the course in relation to future social purposes. Some of the students mentioned that they liked the Oral Communication for Occupational and Social Purposes course because it helped them improve their social communication skills. These skills included skills such as "how to approach people and how to converse with them appropriately", "how to handle or adapt to different audiences or situations" and "how to deal with people of different ages, gender and social class" as mentioned in the following extracts:

"This course taught me to communicate effectively according to specific purposes." (Student D)

"I will be able to present myself to the society better when all the knowledge I gained has been applied." (Student F)

"For the social purpose, I think that I can use what I learn to strengthen my relationship with others such as by giving inspirational, motivational, and other speeches." (Student A)

During the interview, Student $\mathrm{H}$ commented that she gained from the interactions in class:

"I can now work well in a team and be able to communicate effectively with course mates and friends." 
Other benefits mentioned are:

"This course is full of information and practical advice that I can use to improve my interpersonal skills.” (Student J)

"I can now speak my mind in an organised way." (Student C)

"I am not afraid anymore to talk in front of a huge crowd or an audience." (Student I)

The responses indicate that the students believed that the oral communication skills in English would be useful for their future social interaction as they become more confident in expressing their ideas and taking part in discussions. These beliefs were also evident in other studies mentioned in the literature (e.g., Masmaliyeva, 2014; Hanafi Zaid \& Kamarudin, 2011; Talif \& Noor, 2009).

\subsection{Theoretical Applications for Future Occupational Purposes}

Due to an increase in international interactions and business operations, good oral communication skill is important in order to function effectively in the professional setting (Živković \& Stojković, 2011). Equipping graduates with good oral skills will help them in conducting and participating in future meetings, exchanging knowledge, and communicating with future clients. This section examines students' perceptions regarding the application of the theories learnt for future occupational purposes.

In the majority of the responses, the students indicated that audience analysis, persuasion techniques, and group communication in problem solving were important for future occupational purposes. The following extracts demonstrate the perceived relevance of theories learnt in future work environment:

"I believe all the theories learnt are relevant and applicable for my future use. What I learnt about the kinds of leadership in small groups will be important when I join a company." (Student C)

"The theory of communication, group norms and basic communication principles can be applied during presentations and when managing tasks in the workplace." (Student E)

Based on the responses during the interviews, students perceived that they had developed their communication skills using the techniques, theories and guidelines in the course. The practice they had during the course gave them the opportunity to communicate their needs, ideas and opinions and helped them improve their organisational skills. They felt that they learnt how to engage the audience and appeal to their emotions using the techniques of persuading. They reported that they were more aware of "the use of different and correct words in order to persuade effectively".

\subsection{Theoretical Applications for Future Social Purposes}

The students reported that the theories would be useful in helping them express their opinions better in social situations. For example, the following extracts reflect the students' views regarding the usefulness of the theories learnt.

"I can lead a group of friends if we are in a discussion." (Student A)

"To a certain extent, the communication theories I have learnt help me blend in social groups." (Student H)

"I am able to share my ideas with others better after learning the theories." (Student F)

All in all, the students had a very positive attitude towards the theories and guidelines taught in the course. They were positive in their beliefs about the benefits and usefulness of the theories in future social interactions. They agreed that the theories helped them to interact with others better.

\subsection{Issues and Challenges Experienced during the Course}

The students were asked to comment on the main challenges encountered by them when they were carrying out the oral activities in the course. The challenges faced by the students were related to issues concerning the course content and assignments. Generally, the students were of the opinion that the time for completing the assignments and the time provided for practising their presentations were too limited. According to the students, the time constraint increased their anxiety regarding public speaking. They suggested that the time for practising their presentations be lengthened. The students mentioned that some of the difficulties they faced when participating in class discussions were having little time to think of responses, asking appropriate questions and competing for turns in on-going discussions.

Based on the interviews, the main challenges faced by the students are lack of time, difficulties in finding the relevant information, choosing and organising points while preparing for tutorials and assignments, and having to memorise points for the presentations and group discussions. These challenges are mentioned in the following extracts:

"I couldn't find the relevant information." (Student B) 
"There was too little time." (Student D)

These sentiments were also expressed by other students:

"My busy schedule made it hard for me to spend more time on preparing for tutorials." (Student F)

"There was too much information and this caused confusion." (Student H)

The students also mentioned the difficulties they experienced with oral presentations, particularly with expressing ideas in a spontaneous speech. However, they commented that they got less nervous when delivering the speech and began to relax after a few practices. The students found the video assignment for the persuasive speech challenging as they had difficulties finding the proper equipment, producing good quality video, meeting the deadline and memorising points. Student C and Student I made the following comments:

"I did not have proper equipment to record my video." (Student C)

"The quality of my video was poor because I used poor quality video recorder." (Student I)

While students agreed that they needed to develop their speaking skills, most of the students felt challenged by the amount of reading expected of them and that they needed more time to memorise the points for their presentations. Some of the difficulties and challenges faced by students when preparing and giving presentations, and participating in discussions can be found in similar studies (Al-Nouh et al., 2015; Radzuan \& Kaur, 2011; Zulkurnain \& Kaur, 2011; Ramirez, 2010).

\section{Conclusion}

In summary, the findings show that the students perceived that they had developed their communication skills using the theories, techniques, and guidelines in the course. Among the benefits of presentations identified is the development of skills demanded by employers such as gathering, analysing, planning, organising and presenting knowledge efficiently and accurately for specific audiences (Masmaliyeva, 2014; Živković, 2014; Hanafi Zaid \& Kamarudin, 2011; Talif \& Noor, 2009).

Despite the positive aspects of the course, students did have lack of confidence in giving presentations and problems with applying the theories learnt. A few of the students expressed boredom due to long lectures. They complained about having little time to read articles and having to spend a lot of time to prepare and memorise points for their presentations. These were the common challenges mentioned during the interviews.

Good communication skills are required by graduates as they are expected to give presentations at their workplaces and interact socially with clients and colleagues. These tasks are part of almost every professional environment as every professional is involved in some aspects of communication such as communicating with other professionals at meetings, seminars and conferences (Živković, 2014; Hanafi Zaid \& Kamarudin, 2011; Gray, 2010; Talif \& Noor, 2009; Kavanagh \& Drennan, 2008).

This study contributes to a better understanding of the range of student experiences, the positive and negative aspects of an oral communication course, and the challenges that students face in meeting the requirements of such a course. It will also provide valuable information for designing an oral communication course that meets the needs of students and potential employers.

This study was not without limitations. As an exploratory study, a small purposive sampling procedure was appropriate, but this limits the generalization of the results. First, the reported study involved ten ESL students since it only involved one public research university in Malaysia. Future research should attempt to replicate a bigger number of interview participants which could be purposely selected from a number of other universities that might give a clearer picture about the effectiveness of oral communication courses in different universities and also to identify the specific employable skills that are lacking in graduates with regards to oral communication.

\section{Recommendations}

Universities should provide students with employability skills demanded by employers. Students need the opportunity to develop and practise communication skills for professional development, personal and social efficacy that will prepare them for their workplace environment. Teaching students to prepare effective oral presentations implies training them to be critical and this improves the quality of thought. Thus, teaching the theories and guidelines of Oral Communication for Social and Occupational Purposes at the university level needs to occupy a significant part of the curriculum to produce graduates who are able to communicate professional knowledge to other professionals.

In designing an oral communication course:

1. Students should be provided with more opportunities to practise oral communication skills inside and outside the classroom.

2. Students should be given more time to prepare and practise their presentations. It may be helpful to 
videotape the students' presentations so that students may be able to improve on their presentations and view their progress.

3. Technical assistance and proper equipment should be provided if students are required to videotape their presentations.

4. Students should be given more opportunities to participate in group discussions to encourage them to interact with one another and express their opinions.

5. Students should be provided with clearer instructions and guidance on the application of theories.

\section{References}

Al-Nouh, N. A., Abdul-Kareem, M. M., \& Taqi, H. A. (2015). EFL College Students' Perceptions of the Difficulties in Oral Presentation as a Form of Assessment. International Journal of Higher Education, 4(1), p136. http://dx.doi.org/10.5430/ijhe.v4n1p136

Cappel, J. J. (2001). Entry-level IS job skills: A survey of employers. The Journal of Computer Information Systems, $42(2), 76$.

Gray, F. E. (2010). Specific oral communication skills desired in new accountancy graduates. Business communication quarterly, 73(1), 40-67. http://dx.doi.org/10.1177/1080569909356350

Hanafi Zaid, Y., \& Kamarudin, H. (2011). Oral communication needs of Mechanical Engineering undergraduate students in UTM: as perceived by the learners. UNSPECIFIED, 1-8.

Kadir, K. A., \& Noor, W. S. W. M. (2014). Language Learning Strategies of Graduates for Future Employment-An Overview. Research in Business and Management, 1(2), pp-1. http://dx.doi.org/10.5296/rbm.v1i2.5091

Kavanagh, M. H., \& Drennan, L. (2008). What skills and attributes does an accounting graduate need? Evidence from student perceptions and employer expectations. Accounting \& Finance, 48(2), 279-300. http://dx.doi.org/10.1111/j.1467-629X.2007.00245.x

Luna, J. L. N. (2004). An English for Occupational Purposes Curriculum for ESL Culinary Arts Students. Master of Arts in English, California State University, Dominguez Hills.

Malaysia Education Blueprint, (2015). Ministry of Education Malaysia. Retrieved from www.moe.gov.my, Putrajaya Malaysia.

Masmaliyeva, A. P. D. L. (2014). Using Affective Effectively: Oral Presentations in EFL Classroom. Journal of Language and Literature, 10, 145-154.

Mechraoui, I. S. A., Noor, Z. M., Ibrahim, E. H. E., Muhamad, A. J., \& Malek, F. A. (2013). Stakeholders' Perceptions of an English for Occupational Purposes Course. World Applied Sciences Journal, 21, 73-87.

Mohamad Zasfirul Zainal Abidin, 2010. The Proficiency and Perceptions of English among Top Management Staff in Malaysia. M.A., International 5(4): 306-321. Islamic University of Malaysia, Kuala Lumpur.

Radzuan, N. R. M., \& Kaur, S. (2011). Technical oral presentations in English: Qualitative analysis of Malaysian engineering undergraduates' sources of anxiety. Procedia-Social and Behavioral Sciences, 29, 1436-1445. http://dx.doi.org/10.1016/j.sbspro.2011.11.383

Rajprasit, K., Pratoomrat, P., \& Wang, T. (2015). Perceptions and Problems of English Language and Communication Abilities: A Final Check on Thai Engineering Undergraduates. English Language Teaching, 8(3), p111. http://dx.doi.org/10.5539/elt.v8n3p111

Ramírez, V. A. C. (2010) Students' Perceptions about the Development of their Oral Skills in an English as a Foreign Language Teacher Training Program. Unpublished Ph.D thesis. Universidad Tecnológica De Pereira, Columbia.

Robles, M. M. (2012). Executive perceptions of the top 10 soft skills needed in today's workplace. Business Communication Quarterly, 75(4), 453-465. http://dx.doi.org/10.1177/1080569912460400

Stapa, S. H., Maasum, T. N. R. T., Mustaffa, R., \& Darus, S. (2008). Workplace written Literacy and its effect on the curriculum. GEMA: Online Journal of Language Studies, 8(1), 23-33.

Talif, R., \& Noor, R. (2009). Connecting language needs in the workplace to the learning of English at tertiary level. Pertanika Journal of Social Science \& Humanities, 17(2), 67-77.

Živković, S., \& Stojković, N. (2011). Modernization of English as Foreign Language Studies in University Education. University Education in Transition.

Živković, S. (2014). The importance of oral presentations for university students. Mediterranean Journal of Social Sciences, 5(19), 468. http://dx.doi.org/10.5901/mjss.2014.v5n19p468

Zulkurnain, N., \& Kaur, S. (2014). Oral English Communication Difficulties and Coping Strategies of Diploma of Hotel Management Students at UiTM. 3L: Language, Linguistics, Literature ${ }^{\circledR}, 20(3)$. http://dx.doi.org/10.17576/3L2014-2003-08. 